\title{
Fatores de saúde mental associados à não adesão à terapia anti-retroviral: uma revisão sistemática
}

Mental health factors associated with non-adherence to antiretroviral therapy: a systematic review Factores de salud mental asociados con la no adherencia al tratamiento antirretroviral: una revisión sistemática

\begin{abstract}
RESUMO
Introdução: Fatores que contribuem com a não adesão são ameaças à complexidade do tratamento, que é de longa duração. Estes, podem influenciar na vulnerabilidade bio-lógica dos pacientes e causar agravos. Objetivos: Avaliar os fatores de saúde mental relacionados à não adesão à terapia anti-retroviral (TARV). Métodos: Foi realizada uma revisão sistemática nas bases Web of Science e MEDLINE com os termos "HIV", "Tera-pia antiretroviral" e "Não adesão", no período temporal de 2012 a 2018. Resultados: Após a conclusão da pesquisa, foram encontrados 57 artigos que correlacionaram a TARV com os fatores de saúde mental que interferem na adesão ao tratamento. No ge-ral, podemos identificar quatro aspectos que influenciam significativamente a adesão: a) drogas (uso de álcool e drogas); b) Depressão; c) Ansiedade; d) estigma. Conclusão: a avaliação e o tratamento de fatores psicossociais devem ocorrer durante o acompa-nhamento da terapia de novos pacientes e também ser parte integrante da rotina e da continuidade do tratamento do HIV.
\end{abstract}

DESCRITORES: HIV; Terapia antiretroviral; Não Adesão.

\section{ABSTRACT}

Introduction: Factors that contribute to non-adherence are threats to the complexity of the treatment, which is long lasting. These can influence the biological vulnerability of patients and cause aggravations. Objectives: To evaluate mental health factors related to non adherence to antiretroviral therapy (ART). Methods: A systematic review was carried out in the Web of Science and MEDLINE databases with the terms "HIV", "An-tiretroviral therapy" and "Non-adherence", from 2012 to 2018.Results: After completion of the research, 57 articles were found that correlated ART with mental health factors that interfere with treatment adherence. In general, we can identify four aspects that sig-nificantly influenced adherence: a) drugs (alcohol and drug use); b) depression; c) anxie-ty; d) stigma. Conclusion: The evaluation and treatment of psychosocial factors should take place during the follow-up of new patients' therapy and also be part of the routine and continuity of HIV treatment.

DESCRIPTORS: HIV; Antiretroviral Therapy; Non Adherence.

\section{RESUMEN}

Introducción: Los factores que contribuyen a la no adherencia son amenazas a la com-plejidad del tratamiento, que es de larga duración. Éstas pueden influir en la vulnerabili-dad biológica de los pacientes y causar agravios. Objetivos: Evaluar los factores de salud mental relacionados con el incumplimiento del tratamiento antirretroviral (TAR). Métodos: : Se realizó una revisión sistemática en las bases de datos Web of Science y MEDLINE con los términos "HIV", "Terapia antirretroviral" y "No adherencia", en el pe-ríodo de 2012 a 2018. Resultados: Tras la finalización de la investigación, se encontra-ron 57 artículos que correlacionaban la terapia antirretroviral con factores de salud men-tal que interfieren con la adherencia al tratamiento. En general, podemos identificar cua-tro aspectos que influyeron significativamente en la adhesión: a) drogas (alcohol y con-sumo de drogas); b) depresión; c) ansiedad; d) estigma. Conclusión: La evaluación y el tratamiento de los factores psicosociales deben tener lugar durante el seguimiento de la terapia de los nuevos pacientes y también formar parte de la rutina y la continuidad del tratamiento del VIH.

DESCRIPTORES: HIV; Terapia antirretroviral; No Adherencia.

RECEBIDO EM: 22/07/2020 APROVADO EM: 08/09/2020 


\section{Poliana Moreira de Medeiros Carvalho}

Farmacêutica, Doutora pelo Programa de Pós-Graduação em Ciências da Saúde da Faculdade de Medicina do ABC (FMABC), Santo André, SP, Brasil.

ORCID: 0000-0002-2470-1923

\section{Raimundo Monteiro da Silva Neto}

Graduando do Curso de Enfermagem, Centro Universitário de Juazeiro do Norte (UNIJUAZEIRO), Juazeiro do Norte, CE, Brasil. ORCID: 0000-0001-9949-1740.

\section{Modesto Leite Rolim Neto}

Professor da Faculdade de Medicina da Universidade Federal do Caririr - UFCA, Pós-Doutor em Saúde Públi-ca pela Universidade de São Paulo - USP. Doutor em Ciências da Saúde pela Universidade Federal do Rio Grande do Norte - UFRN.

ORCID: 0000-0002-7715-5508

\section{INTRODUÇÃO}

A Síndrome da Imunodeficiência Adquirida - AIDS é uma pandemia ${ }^{1}$ causada pelo Vírus da Imunodeficiência Humana - HIV, que ao atingir o organismo do indivíduo, ataca os linfócitos T CD4+ que fazem parte do sistema imu$n e^{2}$ provocando o surgimento de di-versos tipos de doenças oportunistas ${ }^{3}$.

No ano de 2015 havia aproximadamente 36, 7 milhões de pessoas com HIV no mundo ${ }^{4}$. Em 2016, foi registrado que cerca de $77 \%$ dos indivíduos que reconhecem que convi-vem com este vírus estavam em uso de antirretrovirais e destes, $82 \%$ apresentavam carga viral suprimida. Porém, de 85 países que relataram sobre AIDS neste mesmo ano, um terço ainda apresentava células T CD $4+$ menores que $200{ }^{4}$ que podem apresentar maiores possibilidades de progressão da doença e aumento dos riscos de mortalidade 5 .

O surgimento de diversas classes de antirretrovirais com diferentes mecanismos de ação 6 foi sugestivo ao uso de classes combinadas, TARVC - Terapias Antirretrovirais Combinadas ${ }^{7,8}$ que passaram a serem consideradas mais eficazes que tratamentos com um fármaco de único princípio ativo ${ }^{9}$. O desenvolvimento das Terapias Antirretro-virais proporcionou redução da morbidade e mortalidade dos indivíduos que vivem com HIV/ AIDS ${ }^{10}$.

As terapias antirretrovirais são importantes não só porque garantem qualidade de vida às pessoas que convivem com HIV/AIDS, mas também porque reduzem os riscos de transmissibilidade a outros indivíduos ${ }^{5}$. Mas o sucesso no uso destes fármacos depende entre outros fatores, da taxa de adesão do paciente ao tratamento ${ }^{11}$.

Existe uma melhor adesão terapêutica quando o indivíduo compreende que os fármacos em uso lhe garantem melhor condição de saúde, fato este que apresenta influência dire-ta sobre a carga viral e contagem de linfócitos T CD4+ ${ }^{12}$.Tratamentos antirretrovirais quando realizados corretamente podem reduzir a carga viral a níveis indetectáveis e apresentar aumento no número de linfócitos $\mathrm{T} \mathrm{CD} 4+{ }^{13}$.

Em casos de não adesão ao tratamento, o maior agravante é o desenvolvimento de ce-pas virais multirresistentes capazes de gerar prejuízos individuais e coletivos ${ }^{14}$.Fatores que contribuem com a não adesão são ameaça à complexidade do tratamento, que é de longa duração, apresentação de diversos efeitos colaterais ${ }^{15}$, além dos riscos de intera-ções entre fármacos e toxicidade 6. Apesar dos benefícios dos antirretrovirais, podem ser observadas, em alguns pacientes sentimentos de ansiedade, depressão, ira, culpa, revolta (raiva), estresse, obsessões e auto-observação.

Podendo estes fatores influenciar na adesão ao tratamento, afetando a vulnerabilidade biológica do paciente e causando agravamento do quadro clínico da doença ${ }^{16}$. Desta forma, a presença destes fatores comportamentais pode determinar se o indivíduo está dentro dos padrões de obtenção de resultados ótimos no tratamento de HIV/AIDS ${ }^{12}$
A pesquisa foi conduzida sob a estrutura do acrônimo PICO formulado através da per-gunta norteadora de pesquisa: "Quais são os fatores de saúde mental relacionados à não adesão à TARV?”. Sendo: $\mathrm{P}($ População $)=$ Pacientes com TARV; I (Intervenção) = Adesão adequada; C (Comparador $)=$ Fatores de não adesão versus aderência; $\mathrm{O}$ (Re-sultado) $=\mathrm{Me}$ lhorar o controle da Terapia do HIV.

\section{MÉTODO}

Realizamos uma revisão sistemática sobre terapia anti-retroviral HIV e aderência ao tra-tamento relacionados a fatores de saúde mental publicados em bases de dados eletrôni-cos previamente selecionados. Nosso estudo foi realizado de acordo com os Itens de Relatório Preferidos para Revisões Sistemáticas e Meta-análises (PRISMA) ${ }^{17}$.

Neste artigo, realizamos as buscas nas bases de dados online Web of Science e Medical Literature Analysis and Retrieval System Online (MEDLINE), usando o limite temporal de artigos publicados no período de 2012 a 2018. A análise deste período específico de-ve-se à relevância dos artigos publicados nos últimos 7 anos sobre terapêutica anti-retroviral. A partir deste ponto, houve um enorme aumento de artigos visando a desco-berta de fatores que influenciam a adesão ao tratamento em busca de melhores resulta-dos prognósticos.

\section{Estratégia de busca}

Os seguintes descritores foram utiliza- 
dos na busca e combinados pelo operador booleano "AND"

\#1. "HIV" (Medical Subject Headings $[\mathrm{MeSH}])$;

\#2. "Terapia antiretroviral" (termo $\mathrm{MeSH})$.

A palavra-chave "Não aderência" também foi usada.

Foram encontrados 267 resultados no banco de dados Web of Science e 232 resultados na base de dados MEDLINE. Além disso, utilizamos o filtro "Título, resumo, chave" nos bancos de dados, o filtro
"Texto completo gratuito" e selecionamos apenas artigos originais.

\section{Elegibilidade}

Os critérios para a inclusão são os seguintes: (1) estudos que relacionaram a adesão da tera-pia anti-retroviral com fatores de saúde mental; (2) artigos que tratam da relação do T CD4 com a carga viral (3) artigos que incluíram no título pelo menos uma das combinações de descritores na estratégia de busca; e (5) ser estudo primário. Foram exclusos os estudos que abordaram: (a) Apenas dados epide-

Figura 1 - Fluxograma descrevendo a estratégia de busca e seleção de estudos os itens Preferenciais de Relatórios para Revisão Sistemáticas e Meta-Análises (PRISMA).

PRISMA Diagrama de fluxo 2009
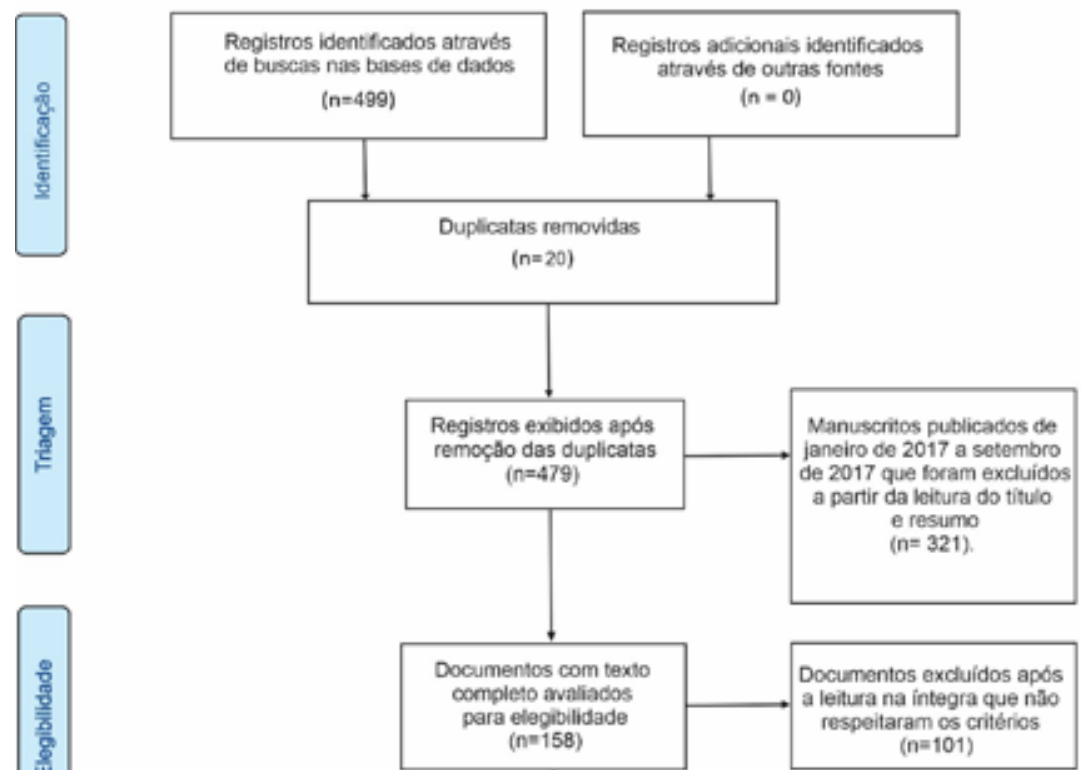

Estudos incluidos na sintese qualitativa

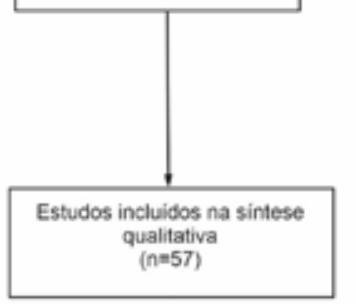
$(n=101)$

miológicos; (d) Apenas terapia; (e) Apenas fatores socio-econômicos; (f) Estudos secundários.

\section{Extração de dados e categorização}

Cada artigo foi lido na íntegra por dois pesquisadores de maneira individual $\mathrm{e}$ as informações extraídas foram inseridas em uma tabela com os seguintes dados: ordem cronológica, Au-tor/ano e principais desfechos.

As informações foram relacionadas entre fatores da não adesão TARV e saúde mental. Além disso, para melhor analisar os dados, dividimos nossos resultados em quatro categorias: de-pressão, estigma, ansiedade e drogas (uso de drogas e álcool). Alguns estudos foram inseri-dos em mais de uma categoria, na medida em que esta disposição ilustra claramente quais aspectos psicológicos devem ser explorados em um paciente sob terapia anti-retroviral.

\section{RESULTADOS}

Após a conclusão da pesquisa nas duas bases de dados (Web of Science e MEDLINE), encontramos 57 artigos que correlacionaram a TARV com fatores de saúde mental que interferem na adesão ao tratamento (Figura 1). No geral, podemos identificar quatro aspectos que influenciam significativamente a adesão: a) drogas (uso de álcool e dro-gas); b) Depressão; c) Ansiedade; d) estigma.

Nossa pesquisa evidenciou 40 artigos que relacionavam medicamentos (Uso de Álcool e Drogas) com TARV, 25 artigos que relatavam depressão, 4 artigos que relatavam ansie-dade e 9 artigos que relacionavam estigma (Quadro 1).

Em síntese do nosso estudo, construímos um esquema de meta-resumo (Figura 2) que pode ilustrar nossos principais resultados. Os principais aspectos dos fatores mentais evidenciados para influenciar diretamente na não adesão à TARV foram categorizados em quatro esferas psicológicas: Drogas (Uso de Álcool e Drogas), Depressão, Ansieda-de e Estigma.

Em suma, o álcool foi o fator mais relevante relacionado à não adesão à TARV, acima e além dos sintomas depressivos. 


\section{artigo}

Carvalho, P.M.M.; Silva Neto, R.M.; Rolim Neto, M.L.

Fatores de saúde mental associados à não adesão à terapia anti-retroviral: uma revisão sistemática

Quadro 1- Os principais achados de cada artigo relacionando os fatores de saúde men-tal à influência da adesão ao TARV.

\begin{tabular}{|c|c|c|}
\hline NÚMERO & AUTORES E ANO & PRINCIPAIS ACHADOS \\
\hline 1 & $\begin{array}{l}\text { Gross et al., } \\
\qquad(2016)\end{array}$ & $\begin{array}{l}\text { Os participantes com menor probabilidade de serem aderentes foram aqueles com maior sofrimento } \\
\text { psicológico e envolvidos no uso semanal de cannabis ( } 69 \% \text { eram não aderen-tes). }\end{array}$ \\
\hline 2 & $\begin{array}{l}\text { Betancur et al., } \\
\text { (2017) }\end{array}$ & $\begin{array}{l}\text { A avaliação dos sintomas de ansiedade e depressão deve ser feita ao longo da terapia, pois ambas } \\
\text { as condições psicológicas estão associadas à ade-são do paciente, sucesso do tratamento e, por } \\
\text { fim, à qualidade de vida do paciente. }\end{array}$ \\
\hline 3 & $\begin{array}{l}\text { Mukui et al., } \\
(2016)\end{array}$ & $\begin{array}{l}\text { Intervenções direcionadas especialmente para jovens e pessoas de áreas rurais, para melhorar os re- } \\
\text { sultados de adesão, bem como programas de tratamento que incluam apoio psicossocial como medida } \\
\text { preventiva para minimizar o abuso de substâncias e o risco de falha do tratamento. }\end{array}$ \\
\hline 4 & $\begin{array}{l}\text { Bogart et al., } \\
(2016)\end{array}$ & $\begin{array}{l}\text { Redes sociais com maior capacidade de apoio social podem ajudar a ame-nizar a relação entre estigma } \\
\text { e não-adesão. }\end{array}$ \\
\hline 5 & $\begin{array}{l}\text { Muessig et al., } \\
(2014)\end{array}$ & $\begin{array}{l}\text { Encontrou uma relação entre uso de álcool e adesão consistente com a lite-ratura global (Azar, Springer, } \\
\text { Meyer, \& Altice, 2010; Braithwaite \& Bryant, 2010) mas não identificado em estudos chineses anteriores } \\
\text { (H. Wang et al.,, 2008; X. Wang \& Wu, 2007). }\end{array}$ \\
\hline 6 & Roux et al., (2014) & $\begin{array}{l}\text { O acesso ao tratamento do VHC deve ser encorajado, assim como o trata-mento adequado para a de- } \\
\text { pressão nessa população, para melhorar a ade-são e a resposta à TARV. }\end{array}$ \\
\hline 7 & $\begin{array}{l}\text { Tufano et al., } \\
(2015)\end{array}$ & $\begin{array}{l}\text { Sintomas depressivos foram relacionados a presença de padrões de falta de doses, não adesão ao tra- } \\
\text { tamento e falha virológica. }\end{array}$ \\
\hline 8 & $\begin{array}{l}\text { Kalichman et al., } \\
\text { (2014) }\end{array}$ & $\begin{array}{l}\text { Os maus resultados do tratamento do HIV e a não adesão foram prevalentes entre os adultos tratados } \\
\text { para a infecção pelo HIV que bebem álcool. }\end{array}$ \\
\hline 9 & $\begin{array}{l}\text { Pellowski et al., } \\
\text { (2016) }\end{array}$ & $\begin{array}{l}\text { Regressões multivariadas multinivel mostraram que essas crenças de toxici-dade previam doses diárias } \\
\text { perdidas de medicação, além da quantidade de álcool consumido, depressão e preocupações com me- } \\
\text { dicamentos em geral. }\end{array}$ \\
\hline 10 & $\begin{array}{l}\text { Paolillo et al., } \\
\text { (2017) }\end{array}$ & $\begin{array}{l}\text { Rastreio de PVHS (Pessoas vivendo com HIV / AIDS), anos de escolaridade e carga viral plasmática po- } \\
\text { dem fornecer aos clínicos para uma melhor indica-ção dos pacientes com maior risco de não adesão à } \\
\text { TARV em comparação com o autorrelato. }\end{array}$ \\
\hline 11 & $\begin{array}{l}\text { De Boni et al } \\
(2016)\end{array}$ & $\begin{array}{l}\text { A adesão foi pior nos finais de semana em comparação aos dias da sema-na: a diferença foi pequena } \\
\text { no início do tratamento, aumentou com o tempo e esteve associada ao consumo excessivo de álcool. }\end{array}$ \\
\hline 12 & Magidson (2015) & $\begin{array}{l}\text { A importância do castigo ambiental na relação entre depressão e adesão à medicação pode informar } \\
\text { futuros esforços de intervenção para essa popu-lação. }\end{array}$ \\
\hline 13 & $\begin{array}{l}\text { Jordan et al., } \\
(2015)\end{array}$ & $\begin{array}{l}\text { O uso ativo de drogas e a duração da TARV aumentam as chances de ade-rência subótima à TARV. Os } \\
\text { resultados sugerem que aqueles que injetaram drogas nos seis meses anteriores tiveram mais do que o } \\
\text { dobro de probabi-lidade de relatar baixa adesão ao TARV do que aqueles que não injetaram drogas nos } \\
\text { seis meses anteriores. Os programas de terapia de manutenção com metadona (MMT) demonstraram } \\
\text { facilitar significativamente a TARV efi-caz entre usuários de drogas (DU) no Vietnã. }\end{array}$ \\
\hline 14 & $\begin{array}{l}\text { Blashill, Gor-don, } \\
\text { Safren (2015) }\end{array}$ & $\begin{array}{l}\text { As preocupações relacionadas à aparência são prevalentes entre os indiví-duos infectados pelo HIV e } \\
\text { estão associadas ao aumento da depressão e à não adesão à TARV. Os resultados do presente estudo } \\
\text { revelaram que, entre uma amostra deprimida e dependente de opióides de homens e mulheres infec- } \\
\text { tados pelo HIV, a relação temporal entre preocupações com a aparência e a não adesão à TARV era } \\
\text { mediada pela gravidade da depressão, mesmo em uma amostra com níveis elevados de depressão. e, } \\
\text { portanto, um alcan-ce potencialmente restrito, devido à qualificação para um diagnóstico de-pressivo. }\end{array}$ \\
\hline 15 & $\begin{array}{l}\text { Belenky et al., } \\
(2014)\end{array}$ & $\begin{array}{l}\text { Uma medida contínua de sintomas depressivos no início do estudo associ-ou-se positivamente com a } \\
\text { não adesão à TARV, tanto no início como na visita de acompanhamento de } 12 \text { meses. Esta relação posi- } \\
\text { tiva manteve-se nos resultados brutos e ajustados. }\end{array}$ \\
\hline 16 & $\begin{array}{l}\text { Magidson et al., } \\
\text { (2016) }\end{array}$ & $\begin{array}{l}\text { Os dados demonstraram um efeito mediador significativo da estrutura do estilo de vida na relação entre } \\
\text { os sintomas depressivos e as duas medidas comportamentais de adesão (tomada de dose e tempo de } \\
\text { dose). Esses achados sugerem que o grau de estrutura das atividades diárias de uma pessoa pode ser } \\
\text { um caminho importante pelo qual a depressão interrompe o comportamento de adesão e promove a } \\
\text { compreensão de como a depres-são afeta a adesão à TARV. }\end{array}$ \\
\hline
\end{tabular}




\begin{tabular}{|c|c|c|}
\hline 17 & $\begin{array}{l}\text { Kalichman et al., } \\
\text { (2016) }\end{array}$ & $\begin{array}{l}\text { A maioria dos pacientes teve uma percepção positiva dos resultados da TARV, o que influenciou seu } \\
\text { comportamento de adesão. Além disso, o me-do de revelar o status de HIV por causa do estigma as- } \\
\text { sociado à doença também foi mostrado como um importante contribuinte para a não-adesão à TARV. }\end{array}$ \\
\hline 18 & $\begin{array}{l}\text { Gebrezgabher et } \\
\text { al., (2017) }\end{array}$ & $\begin{array}{l}\text { O uso de substância e tendo sintoma de depressão foram encontrados fato-res determinantes inde- } \\
\text { pendentes da não adesão do medicamento ART. O estudo mostrou que os indivíduos usuários de subs- } \\
\text { tâncias HIV- positivas foram mais propensos a não adesão, em comparação com aqueles que tinham } \\
\text { sintomas de depressão }\end{array}$ \\
\hline 19 & Azar et al., (2015) & $\begin{array}{l}\text { Os períodos de uso de heroína injetável e o uso de cocaína por injeção fo-ram associados de forma in- } \\
\text { dependente e negativa a uma menor probabili-dade de adesão ótima à TAR, enquanto o envolvimento } \\
\text { no MMT foi associ-ado a níveis mais altos de adesão ótima. Os resultados apóiam a necessi-dade de } \\
\text { estimular esforços para melhorar o acesso ao tratamento para o uso problemático de substâncias entre } \\
\text { os indivíduos que vivem com HIV / AIDS. }\end{array}$ \\
\hline 20 & $\begin{array}{l}\text { Sharma et al., } \\
\text { (2016) }\end{array}$ & $\begin{array}{l}\text { A história de vida do uso problemático de álcool pode não impactar a ade-são à TARV. A adesão à TARV } \\
\text { pode ser alcançada em níveis semelhantes aos pacientes sem histórico de uso problemático de álcool se } \\
\text { o abuso ou dependência cessar no início da medicação. }\end{array}$ \\
\hline 21 & Kim et al., (2017) & $\begin{array}{l}\text { Encontrou-se uma taxa muito alta de não adesão autorreferida. Também foram identificadas várias as- } \\
\text { sociações importantes modificáveis, com a não adesão à TARV, como uso de álcool, violência doméstica } \\
\text { e baixa auto-eficácia do tratamento que ainda permanecem em grande parte não exami-nados na África } \\
\text { Austral. }\end{array}$ \\
\hline 22 & $\begin{array}{l}\text { Denison et al., } \\
\text { (2015) }\end{array}$ & $\begin{array}{l}\text { Fatores significativamente relacionados à adesão incompleta incluíram visitar um curandeiro tradicional, } \\
\text { triagem positiva para abuso de álcool, experimen-tar mais sintomas do HIV, ter um regime de TARV sem } \\
\text { nevirapina e níveis mais altos de estigma internalizado. }\end{array}$ \\
\hline 23 & $\begin{array}{l}\text { Kalichman et al., } \\
\text { (2016) }\end{array}$ & $\begin{array}{l}\text { Usuários ativos de drogas demonstraram baixa adesão aos seus medica-mentos para o HIV. Os resul- } \\
\text { tados mostraram que os indivíduos que afirma-ram que eles intencionalmente sentem falta de tomar } \\
\text { ART quando usam dro-gas endossaram todas as crenças de toxicidade interativa em um grau maior do } \\
\text { que aqueles que não são intencionalmente não aderentes. }\end{array}$ \\
\hline 24 & $\begin{array}{l}\text { Kalichman et al., } \\
\text { (2012) }\end{array}$ & $\begin{array}{l}\text { Má adesão ao tratamento entre homens e mulheres soropositivos que con-somem álcool. Observou-se } \\
\text { uma associação entre a propensão a pular ou interromper a medicação ao beber e o número de dias que } \\
\text { os participantes ingeriram e perderam medicaç̃̃es simultaneamente. Assim, intencionalmente pular ou } \\
\text { interromper a TAR quando a bebida é uma fonte de não-adesão em pessoas vivendo com HIV. }\end{array}$ \\
\hline 25 & $\begin{array}{l}\text { Smith Fawzi et al., } \\
\text { (2016) }\end{array}$ & $\begin{array}{l}\text { Depressão e problemas de conduta foram significativamente associados com a não adesão à TARV en- } \\
\text { tre os jovens que vivem em Ruanda rural, con-forme relatado pelos cuidadores. Em contraste, ansiedade } \\
\text { mista / depres-são, irritabilidade e problemas de conduta (autorrelato) não foram relaciona-dos à ade- } \\
\text { são à TARV. }\end{array}$ \\
\hline 26 & $\begin{array}{l}\text { Panigrahi, Swain, } \\
\text { Mohanty (2015) }\end{array}$ & $\begin{array}{l}\text { A ansiedade está associada à adesão insuficiente à medicação em pacien-tes infectados pelo HIV. O } \\
\text { estudo provou conclusivamente que a não adesão à medicação anti-HIV está associada ao nivel severo } \\
\text { da ansiedade em comparação com os pacientes aderentes. }\end{array}$ \\
\hline 27 & $\begin{array}{l}\text { Pefura-Yone et } \\
\text { al., (2013) }\end{array}$ & O consumo de álcool foi um dos principais determinantes da não adesão. \\
\hline 28 & R et al., (2014) & $\begin{array}{l}\text { Nenhuma evidência de que a adesão ao longo do tempo diferiu entre partici-pantes cognitivamente de- } \\
\text { bilitados e cognitivamente não debilitados; uma melhora significativa e muito semelhante na adesão foi } \\
\text { observada em am-bos os grupos. No entanto, houve evidências de que a depressão moderou a resposta } \\
\text { à intervenção. Os participantes não deprimidos melhoraram sua adesão ao longo do tempo, no entanto, } \\
\text { a melhora entre os participantes deprimidos foi menor e não estatisticamente significativa. }\end{array}$ \\
\hline 29 & $\begin{array}{l}\text { Sauceda et al., } \\
\text { (2016) }\end{array}$ & $\begin{array}{l}\text { A depressão mediava a relação entre abuso sexual na infância e adesão à TARV, com pior adesão dos } \\
\text { participantes nos percentis mais baixos do índice de resiliência. }\end{array}$ \\
\hline 30 & Willie et al., (2016) & $\begin{array}{l}\text { As pessoas vivendo com HIV que sofreram abuso sexual na infância têm menor adesão à medicação } \\
\text { para HIV do que as pessoas que vivem com o HIV sem um histórico de CSA, provavelmente em parte } \\
\text { devido às sequelas de abuso de saúde mental. }\end{array}$ \\
\hline 31 & Tran et al., (2014) & $\begin{array}{l}\text { O estudo constatou que o AUD (Transtorno de Uso de Álcool) ocorre com alta prevalência em grandes } \\
\text { epidemias de HIV / AIDS no Vietnã e apóia e apóia as evidências do efeito negativo do AUD sobre a ade- } \\
\text { são e resultados de TARV em tais epidemias. }\end{array}$ \\
\hline
\end{tabular}




\section{artigo}

\begin{tabular}{|c|c|c|}
\hline 32 & $\begin{array}{l}\text { Batista et al., } \\
(2014)\end{array}$ & $\begin{array}{l}\text { As pessoas que usam drogas tendem a ser mais vulneráveis socialmente e têm um estilo de vida caótico } \\
\text { e instável que influencia a adesão a qualquer tipo de tratamento crônico. O uso de drogas ilícitas tem sido } \\
\text { associado tanto à não adesão quanto à diminuição das respostas viral e imunológica aos antirretrovirais. }\end{array}$ \\
\hline 33 & $\begin{array}{l}\text { Kleinman et al., } \\
\text { (2015) }\end{array}$ & $\begin{array}{l}\text { A depressão foi associada à menor adesão, independentemente da medida utilizada. A depressão afe- } \\
\text { ta negativamente a qualidade de vida e o envolvi-mento nos cuidados, e o tratamento da depressão } \\
\text { pode resultar em melhor adesão. A falta de associaçãa entre estigma e adesão foi surpreendente. Os } \\
\text { indivíduos nas redes de apoio ao HIV estudados aqui podem ter redes sociais mais fortes e melhores } \\
\text { enfrentamentos. }\end{array}$ \\
\hline 34 & $\begin{array}{l}\text { Kekwaletswe and } \\
\text { Morojele (2014) }\end{array}$ & $\begin{array}{l}\text { Cerca de metade dos bebedores masculinos e três quartos das pontuaçães dos Testes de Identificação } \\
\text { de Desordens do Uso de Álcool das mulheres que bebem eram sugestivas de bebida perigosa ou nociva. } \\
\text { A adesão média à TARV autorreferida foi de } 89,7 \% \text {. Houve associação significativa entre nível de uso de } \\
\text { álcool e grau de adesão à TARV. }\end{array}$ \\
\hline 35 & Ferro et al., (2015) & $\begin{array}{l}\text { O estudo destaca a associação forte e significativa de AUDs com a adesão ao TARV abaixo do ideal entre } \\
\text { HSH infectados pelo HIV (homens que fazem sexo com homens) no Peru. Embora a influência de outros } \\
\text { fatores (p.ex., NCl, depressão e estigma) na baixa adesão não tinha sido considerada sig-nificante nessa } \\
\text { amostra. }\end{array}$ \\
\hline 36 & $\begin{array}{l}\text { Kalichman et al., } \\
\text { (2014) }\end{array}$ & $\begin{array}{l}\text { Bebedores e participantes mais pesados que relataram uso de maconha demonstraram menor ade- } \\
\text { são. No geral, quanto maior a quantidade de bebi-da e o maior número de drogas utilizadas, maior a } \\
\text { probabilidade de os parti-cipantes terem uma aderência abaixo do ideal. Comportamentos associados } \\
\text { a crenças sobre a mistura de álcool e medicamentos anti-retrovirais também foram prevalentes entre } \\
\text { PVHS (Pessoas Vivendo com o HIV). }\end{array}$ \\
\hline 37 & $\begin{array}{l}\text { Beer and skar- } \\
\text { binski (2014) }\end{array}$ & $\begin{array}{l}\text { Os fatores associados à menor adesão incluíram idade mais jovem, sexo feminino, depressão, uso de es- } \\
\text { timulantes, uso abusivo de álcool, dosagem maior que uma vez ao dia, maior tempo desde o diagnóstico } \\
\text { de HIV e cren-ças do paciente. }\end{array}$ \\
\hline 38 & $\begin{array}{l}\text { Paparizos et al., } \\
\text { (2013) }\end{array}$ & $\begin{array}{l}\text { A adesão não foi particularmente influenciada pelo encarceramento, dado que a liberação da prisão não } \\
\text { contribuiu para a melhoria, mesmo quando a alta foi devida a grave deterioração clínica e laboratorial. } \\
\text { É óbvio que as causas que levam ao comportamento infrator, que resultaram em encarcera-mento, } \\
\text { também contribuem para a fraca cooperação com os médicos assis-tentes, tanto dentro como fora da } \\
\text { instituição correcional. }\end{array}$ \\
\hline 39 & $\begin{array}{l}\text { Hansana et al., } \\
\text { (2013) }\end{array}$ & $\begin{array}{l}\text { O uso de drogas ilíitas foi um fator contribuinte para a não-adesão. Com base no limiar de } 95 \% \text {. O uso de } \\
\text { drogas ilícitas foi relatado para reduzir o nível de adesão em muitos estudos. Vários estudos documen- } \\
\text { taram que o uso indiscriminado de drogas ilícitas entre PVHS torna o tratamento compli-cado e dificulta } \\
\text { sua qualidade de vida. }\end{array}$ \\
\hline 40 & $\begin{array}{l}\text { Castro } \\
(2015)\end{array}$ & $\begin{array}{l}\text { Barreiras ao nível do paciente se manifestam e interagem com outros siste-mas, como no caso de pa- } \\
\text { cientes com depressão (nível do paciente) encon-trando discriminação estigmatizante (exo-sistema) e } \\
\text { falta de apoio social (micro-sistema), afundando-se mais na depressão. (Terapia antirretroviral altamen- } \\
\text { te ativa) tratamento não aderente. }\end{array}$ \\
\hline 41 & $\begin{array}{l}\text { Bonn-Miller et al., } \\
\text { (2014) }\end{array}$ & $\begin{array}{l}\text { O grupo CD (Dependência de Cannabis) relatou menor adesão e maiores efeitos colaterais dos sintomas } \\
\text { de HIV / ART do que os outros dois grupos, sem diferenças observadas entre NC (uso não-Cannabis) e } \\
\text { C(uso não-dependente de Cannabis). }\end{array}$ \\
\hline 42 & $\begin{array}{l}\text { King RM et al., } \\
\text { (2012) }\end{array}$ & $\begin{array}{l}\text { Depressão, uso de drogas ilícitas e uso de álcool foram associados à não adesão. A análise de regressão } \\
\text { logística ajustada indicou que a dependência de nicotina, o uso de drogas ilícitas, o uso de álcool ea idade } \\
\text { foram asso-ciados à não-adesão. Dependência de nicotina, uso de drogas ilíitas e uso de álcool são } \\
\text { barreiras potencialmente formidáveis para a adesão da TARV às pessoas que fumam. }\end{array}$ \\
\hline 43 & $\begin{array}{l}\text { Teixeira et al., } \\
\text { (2013) }\end{array}$ & $\begin{array}{l}\text { Maior risco de não adesão para pacientes declarando uso de álcool mais drogas ilícitas ou uso de álcool } \\
\text { de alta intensidade. }\end{array}$ \\
\hline 44 & $\begin{array}{l}\text { Kalichman et al., } \\
\text { (2015) }\end{array}$ & $\begin{array}{l}\text { Modelos multivariados controlados para características demográficas e de saúde e frequêência de uso de } \\
\text { álcool mostraram que a não-adesão intencio-nal previu pior adesão ao TARV durante o mês prospectivo } \\
\text { e também previu piores resultados de tratamento, conforme indexados pela carga viral não suprimida. }\end{array}$ \\
\hline
\end{tabular}




\begin{tabular}{|c|c|c|}
\hline 45 & $\begin{array}{l}\text { Moore et al., } \\
(2013)\end{array}$ & $\begin{array}{l}\text { Os usuários atuais de METH (uso de metanfetamina) (uso em } 30 \text { dias) foram significativamente me- } \\
\text { nos aderentes ( } 50 \% \text { de não adesão) do que os usuá-rios de METH + e participantes HIV + / METH, e o } \\
\text { comprometimento neuro-cognitivo foi associado à não adesão ( }<<0,05) \text {. Os distúrbios de uso de METH } \\
\text { estão associados a piores desfechos de doença por HIV e não- ade-são à medicação de TARV. É im- } \\
\text { portante que clínicos e pesquisadores reco-nheçam que os diagnósticos psiquiátricos ao longo da vida } \\
\text { podem impactar os indicadores atuais da doença, mesmo que as pessoas não apresentem sintomas } \\
\text { significativos (isto é, o diagnóstico de transtorno depressivo mai-or) não foi preditivo de não adesão } \\
\text { neste estudo, mas o MDD da vida foi). }\end{array}$ \\
\hline 46 & $\begin{array}{l}\text { Wendorf and Mo- } \\
\text { sack (2012) }\end{array}$ & $\begin{array}{l}\text { Depressão, sinais relacionados ao HIV e crenças de saúde e autocuidado combinados influenciam as es- } \\
\text { tratégias de enfrentamento. As estratégias de enfrentamento, por sua vez, previram se os participantes } \\
\text { poderiam aderir à HAART. }\end{array}$ \\
\hline 47 & Bofill et al., (2014) & $\begin{array}{l}\text { Os motivos identificados para a falta de adesão ou engajamento dos pacien-tes diferiram entre pacien- } \\
\text { tes e profissionais, e os pacientes atribuíram limita-ções à baixa autoeficácia, medo e preocupações com } \\
\text { o HIV e falta de en-volvimento do provedor no tratamento. Em contraste, os provedores se considera- } \\
\text { vam tomadores de decisão no atendimento ao paciente e os paci-entes como responsáveis por sua pró- } \\
\text { pria não-adesão devido à falta de compromisso com sua própria saúde ou devido aos efeitos colaterais } \\
\text { dos medicamentos. Os pacientes relataram as limitações do sistema de saúde e as preocupações com } \\
\text { o HIV contribuíram para a falta de envolvimento, e os provedores identificaram o conhecimento limitado } \\
\text { sobre o HIV e o estigma como problemas adicionais. Ambos concordaram que a doença é crônica e o } \\
\text { vício em substâncias afetam a adesão e a retenção, e concordam com a importância da confiança, ho- } \\
\text { nestidade e comunicação na relação paciente-provedor. }\end{array}$ \\
\hline 48 & $\begin{array}{l}\text { J. Côté et al., } \\
\text { (2016) }\end{array}$ & $\begin{array}{l}\text { Todos os participantes, independentemente da adesão, relataram: baixos níveis de estresse e sintomas } \\
\text { de depressão; alta percepção de autoeficá-cia de medicamentos e apoio social; e uma média de 6,8 } \\
\text { sintomas relacio-nados à medicação para o HIV. Os preditores de adesão foram: alta percep-ção de } \\
\text { autoeficácia de medicamentos e baixo número de efeitos colaterais de medicamentos relatados. }\end{array}$ \\
\hline 49 & $\begin{array}{l}\text { Simoni } \\
(2012)\end{array}$ et al., & $\begin{array}{l}\text { Diferenças raciais / étnicas nos dados demográficos, depressão e abuso de substâncias não explicam o } \\
\text { nível mais baixo de adesão à terapia anti-retroviral em afro-americanos observado em nossa amostra. } \\
\text { Mais pesquisas são necessárias para explicar a disparidade persistente e podem examinar fatores como } \\
\text { desconfiança de provedores, alfabetização em saúde e desi-gualdades no sistema de saúde. }\end{array}$ \\
\hline 50 & $\begin{array}{l}\text { Montoya et al., } \\
\text { (2015) }\end{array}$ & $\begin{array}{l}\text { As barreiras de adesão incluíram o uso de METH, crenças errôneas sobre a adesão às TARV, dificuldades } \\
\text { de memória e planejamento, barreiras sociais e estigma percebido, e problemas de saúde mental. Os } \\
\text { facilitadores da ade-são efetiva à TAR foram estratégias cognitivas compensatórias, promoção do bem- } \\
\text {-estar, apoio à saúde, educação sobre adesão e apoio social. }\end{array}$ \\
\hline 51 & $\begin{array}{l}\text { Magidson et al., } \\
\text { (2017) }\end{array}$ & $\begin{array}{l}\text { Apenas o uso de álcool está sobre os sintomas depressivos e nível de esco-laridade, associado à não } \\
\text { adesão à terapia antirretroviral. }\end{array}$ \\
\hline 52 & $\begin{array}{l}\text { Tedaldi et al., } \\
\text { (2012) }\end{array}$ & $\begin{array}{l}\text { As pessoas que relataram depressão em um determinado ACASI (autoavali-ação assistida por computa- } \\
\text { dor em áudio) apresentaram duas vezes mais probabilidade de relatar a não adesão aos antirretrovirais } \\
\text { no mesmo ACASI; essas pessoas também tinham menos probabilidade de ter carga viral do HIV < } 400 \\
\text { cópias / mL. Ferramentas de triagem padronizadas computadoriza-das auto- administradas podem } \\
\text { identificar indivíduos em risco com depres-são que podem se beneficiar de intervenções para melhorar } \\
\text { a adesão antir-retroviral. }\end{array}$ \\
\hline 53 & $\begin{array}{l}\text { Dagli-Hernandez } \\
\text { et al., (2016) }\end{array}$ & $\begin{array}{l}\text { O nível de educação e o nível de conhecimento sobre HAART foram positi-vamente correlacionados } \\
\text { com o EP (eficácia da farmacoterapia). Esqueci-mento, uso de álcool e falta de conhecimento sobre os } \\
\text { medicamentos foram os fatores mais frequentemente relatados como causa de não adesão. Um novo } \\
\text { parâmetro de autopercepção de adesão do paciente, que é um ins-trumento não invasivo e de baixo } \\
\text { custo, poderia ser aplicado e avaliado tão facilmente quanto o auto-relato (questionário de adesão me- } \\
\text { dicamentosa simplificada) durante o reabastecimento mensal de medicamentos, pois permite o mo- } \\
\text { nitoramento da adesão através da assistência farmacêutica. Portanto, a adesão do paciente à HAART } \\
\text { pode ser avaliada por meio da autopercepção (CEAT- VIH - Cuestionario para la Evaluación da Adhesión } \\
\text { al Tratamiento Antirretroviral) e do teste de carga viral. }\end{array}$ \\
\hline 54 & $\begin{array}{l}\text { Mimiaga et al., } \\
\text { (2013) }\end{array}$ & $\begin{array}{l}\text { A não adesão à terapia anti-retroviral foi associada ao uso de todas as ou-tras substâncias além da } \\
\text { maconha. A co- ocorrência de uso de substâncias, relações sexuais desprotegidas e não-adesão à me- } \\
\text { dicação poderiam atenu-ar os benefícios de saúde pública de testar, tratar e vincular-se a estratégias de } \\
\text { cuidado. São necessários programas de prevenção que abordem essas condições co-prevalentes. }\end{array}$ \\
\hline
\end{tabular}




\section{artigo}

\begin{tabular}{|c|c|c|}
\hline 55 & $\begin{array}{l}\text { Newville, Berg, } \\
\text { Gonzalez, (2015) }\end{array}$ & $\begin{array}{l}\text { Qualquer uso de substâncias ilícitas foi associado à não adesão à HAART. A cannabis era a substância } \\
\text { isolada de abuso mais fortemente associada à não-adesão. Sintomas depressivos aproximaram-se da } \\
\text { significância na aná-lise bivariada. Na análise de regressão, foi encontrada uma interação signifi-cativa } \\
\text { entre o uso de substâncias ilícitas e sintomas depressivos, onde o uso de substâncias ilícitas foi asso- } \\
\text { ciado à não-adesão em indivíduos com sintomas depressivos mais baixos, mas não entre aqueles com } \\
\text { sintomas depressivos em níveis mais altos. Nenhuma substância individual interagiu com sintomas de- } \\
\text { pressivos na adesão. Embora o uso de substâncias e os sintomas depressivos interagissem na adesão } \\
\text { ao HAART, eles não tiveram um efeito sinérgico. }\end{array}$ \\
\hline 56 & $\begin{array}{l}\text { Kader et al., } \\
(2015)\end{array}$, & $\begin{array}{l}\text { O uso nocivo ou prejudicial do álcool e o uso problemático de drogas previ-ram o desaparecimento e a } \\
\text { interrupção da TARV, que, por sua vez, foi asso-ciada à diminuição na contagem de CD4 e progressão } \\
\text { mais rápida da doen-ça pelo HIV e pior desfecho na saúde das PVHS. Os resultados deste estu-do res- } \\
\text { saltam a necessidade de uma abordagem integrada para o gerencia-mento de transtornos por uso de } \\
\text { substâncias em PVHS. }\end{array}$ \\
\hline 57 & $\begin{array}{l}\text { Teshome et al., } \\
\text { (2015) }\end{array}$ & $\begin{array}{l}\text { Os fatores significativamente associados à adesão incompleta incluíam a idade jovem, ser cristão pro- } \\
\text { testante, consumir álcool, ser solteiro e ser membro de uma associação com o HIV. Fatores psicossociais } \\
\text { como estig-ma, depressão e satisfação com o cuidado não estavam associados à ade-são incompleta } \\
\text { no contexto atual. }\end{array}$ \\
\hline
\end{tabular}

Figura 2- Meta-Síntese dos Fatores da Saúde Mental Relacionados à Adesão à TARV

\section{META-SINTESE}

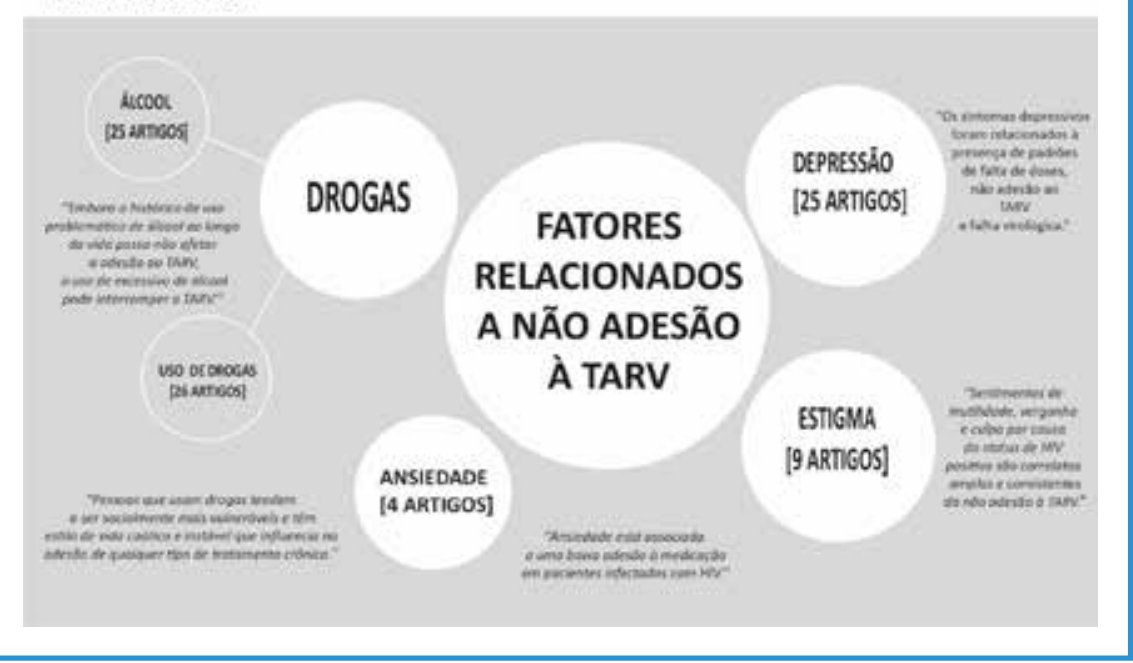

Fonte: Autoria própria.

Em parte, porque as pessoas tendem esquecer ou pular doses ao beber, mas também a crença de que o álcool não pode ser misturado com o TARV estava diretamente associada a não tomar doses.

No que se refere ao uso de drogas ilícitas, evidenciou-se que o uso de drogas interfere na capacidade de tomar o medicamento conforme instruído e as crenças de toxicidade interativa influenciam negativamente na falta de TARV.

Os sintomas de ansiedade e depressão também foram condições psicológicas associa-das à adesão do paciente, sucesso do tratamento, qualidade de vida do paciente. Por fim, o medo de revelar o status de HIV devido ao estigma associado à doença também foi mostrado como um importante contribuinte para a não-adesão à TARV.

\section{DISCUSSÃO}

Os resultados sugerem que a não adesão à medicação TARV é um problema complexo envolvendo fatores do sistema multi-nível na equação. A revisão sistemática encontrou, entre os estudos analisados, cinco áreas de saúde mental associadas à não adesão: es-tigma, depressão, ansiedade, uso de álcool e uso de drogas.

Uma grande quantidade de artigos encontrou uma relação entre o uso de álcool e a ade-são. Vários estudos demonstraram que o álcool estava negativamente associado à ade-são 18-26.Na verdade, os achados atuais apontam para a associação do uso de álcool e não adesão acima e sintomas depressivos ${ }^{27}$.

Um estudo realizado entre uma população de PVHS de baixa renda demonstrou que fumar e beber no último mês explica mais a variação da não-adesão à TARV do que o nível de bebida (ou seja, perigoso versus não perigoso) ${ }^{28}$, e o uso de álcool o mês pas-sado foi altamente correlacionado com a não adesão ${ }^{29}$. Intencionalmente pular ou inter-romper a ART quando a bebida é uma fonte de não-adesão em pessoas vivendo com HIV. 20. Em relação à intencionalidade, outros artigos mostraram que a crença de que o álcool não pode ser misturado à TARV esteve diretamente associada ao não uso de do-ses ${ }^{20,30}$. Beber também pode atrasar a chamada em recargas e pegar prescrições da farmácia ${ }^{20}$.

Por outro lado, os bebedores sem risco têm menor probabilidade de não serem aderen-tes ao TARV do que os consumi- 
dores de alto nível de álcool por dia ${ }^{31}$, e o uso de bebi-das alcoólicas ao longo da vida não afeta a adesão ao TARV ${ }^{32}$. A influência de uma faixa de consumo na adesão e na supressão viral pode ser pequena entre os bebedo-res ${ }^{33}$ e a influência do uso de álcool no último mês não foi relacionada à recente não-aderência à TARV ${ }^{34}$. Ou seja, os resultados aqui apresentados não apontam necessari-amente para o uso de álcool como mais prejudicial para a adesão à TARV do que o uso de outras substâncias ${ }^{31}$.

O uso de drogas está associado à não adesão à TARV em alguns artigos analisados 25,28,42-46,32,35-41. Particularmente, o uso de drogas ilícitas tem associação negativa sig-nificativa com aderência ${ }^{28,39,40}$. Além disso, uma maior frequência de comportamentos de não adesão nos últimos 3 meses foi significativamente associada ao policonsumo de drogas, anfetaminas, crack- cocaína, opiáceos e uso de drogas injetáveis ${ }^{38}$. Usuários de drogas injetáveis têm maior probabilidade de relatar baixa adesão do que aqueles que não injetaram drogas nos últimos seis meses, de acordo com um estudo realizado no Vietnã ${ }^{42}$. $\mathrm{O}$ uso de crack e cocaína foi relacionado à maior frequência de doses perdi-das e à descontinuação do TARV ${ }^{27,41}$.

Já o uso de metanfetaminas (MA) apresenta as dificuldades mais significativas com a não adesão ${ }^{36}$. Participantes de um estudo realizado em San Diego (Califórnia) expres-saram unanimemente que o uso de MA impactou negativamente a adesão ao TARV em seu contexto, o que ignora a realidade, priorizando o uso da MA sobre a adesão, questi-onando a necessidade de TARV, e falta de visão sobre a progressão do $\mathrm{HIV}^{37}$. O uso de drogas pode interferir na capacidade de as pessoas tomarem suas medicações de TARV conforme as instruções ${ }^{45} \mathrm{e}$ as crenças de toxicidade interativa influenciam nega-tivamente a perda de TARV intencionalmente ${ }^{35}$.

Caso contrário, alguns estudos não encontraram associação entre o uso de drogas e a adesão à TARV ${ }^{34,47,48}$. O uso moderado de maconha, em comparação com o não uso, pode não estar significativamente associado ao alívio dos sintomas ou à adesão
Em nossa análise

qualitativa, a

depressão revelou-

se um fator extre-

mamente complexo,

sendo avaliada

por diferentes

dispositivos,

como autorrelato,

diag-nóstico,

questionários e

outras medidas.

à medi-cação ${ }^{47}$. Um estudo realizado na Bahia, Brasil, descobriu que o uso de heroína injetável e o uso de cocaína injetável foram associados de forma independente e negativa a uma menor probabilidade de aderência ótima à TARV 48

Existem estudos que comparam o álcool com o uso de drogas. A associação do consu-mo de álcool e o uso de drogas ilícitas foram fortes preditores de não adesão, mas o uso de álcool ou drogas ilícitas não foi associado à não adesão à TARV em estudo realizado na Bahia, Brasil ${ }^{49}$. Além disso, constatou-se que o uso nocivo e perigoso do álcool teve impactos significativos diretos sobre todas as formas de adesão aos TARV (falta e para-da de TARVs), enquanto o uso problemático de drogas foi encontrado para impactar apenas na falta e não parada de TARV ${ }^{50}$.
Uma pesquisa feita em Connecticut EUA - concluiu que quanto maior a quantidade de bebida e o maior número de drogas utilizadas, maior a probabilidade de os participantes terem uma aderência abaixo do ideal ${ }^{20}$. Uma avaliação prospectiva também descobriu que as pessoas que alegavam ser intencionalmente não-aderentes de fato sentiam falta de seus medicamentos porque estavam bebendo ou usando drogas durante o mês sub-sequente ${ }^{35}$.

O transtorno depressivo maior é uma das doenças mais comuns e subdiagnosticadas em pessoas vivendo com HIV ${ }^{51,52}$, um problema que está intimamente relacionado à adesão da TARV. Em nossa análise qualitativa, a depressão revelou-se um fator extre-mamente complexo, sendo avaliada por diferentes dispositivos, como autorrelato, diag-nóstico, questionários e outras medidas. Um estudo realizado em Salvador, no Brasil, descobriu que sentir-se deprimido foi o maior motivo relatado pelos participantes para interromper o HAART (BETANCUR et al., 2017) ${ }^{53}$.

Outros estudos mostraram que os sintomas depressivos $21,25,43,54,55$ e o diagnóstico de depressão ${ }^{18,56-59}$.Estavam negativamente relacionados à adesão à TARV. Em uma população co-infectada pelo VHC-HIV foi realizada uma pesquisa, cujos resultados indi-caram que quando consideramos aqueles que estavam recebendo terapia antidepressi-va (ADT), os pacientes que apresentam sintomas depressivos durante o tratamento apresentaram um risco maior de não aderência à TARV. aqueles que não foram trata-dos com ADT ${ }^{25}$.

Além disso, outras descobertas demonstraram um efeito mediador significativo da estru-tura do estilo de vida na relação entre os sintomas depressivos e as duas medidas com-portamentais de adesão (tomada de dose e tempo de dose). Os dados não suportam uma relação entre depressão e adesão à dose; no entanto, a depressão estava significa-tivamente relacionada ao momento da dose, sugerindo que a depressão interfere na capacidade de tomar os medicamentos na hora certa, mas não se a dose é realmente tomada ${ }^{27}$. Outra análise interessante diz respeito à intencionali- 
dade das doses omitidas, sugerindo que a depressão pode estar relacionada à falta de aderência quando as doses omitidas são intencionais, em oposição a razões logísticas não intencionais ou mais re-flexivas (por exemplo, simplesmente esquecer, dormir até o momento da dose) ${ }^{27}$.

Em contraste, outros estudos não encontraram associação entre sintomas depressivos e depressão em si com a não adesão ${ }^{28,34,60,61}$. Esses estudos avaliaram outros contextos, como mulheres que sofreram abuso sexual na infância, descobrindo que os componen-tes dos sintomas da depressão não se correlacionaram significativamente à não adesão à medicação ant ${ }^{60}$. Os fumantes também foram avaliados revelando que, embora a depressão e outras variáveis psicossociais desempenhem um papel na não adesão à TARV, a importância desse papel diminui quando avaliada em combinação com outros fatores relevantes nessa amostra de fumantes, ou seja, nível de dependência nicotínica ${ }^{28}$.

Outro fator de saúde mental que pode interferir na adesão é a ansiedade. Um estudo realizado em mulheres vivendo com HIV que sofreram abuso sexual na infância consta-tou que os sintomas de gravidade da ansiedade relacionada ao pânico (ou seja, dificul-dade para respirar, medo de morrer, palpitações cardíacas e asfixia) estão singular e negativamente correlacionados com a adesão à medicação. Isso pode ser explicado pelo fato de que, em particular, mulheres com maior sensação de medo em torno do declínio da saúde e da morte podem evitar comportamentos de enfrentamento para con-trolar a ansiedade, resultando em atitudes de não autocuidado como a não-adesão ao HIV ${ }^{60}$.

Outro estudo concluiu que a não adesão à medicação antirretroviral está associada ao nível grave de ansiedade em comparação com pacientes aderentes ${ }^{62}$. Há também es-tudos que reforçam a importância da ansiedade no processo de adesão ${ }^{53}$. No entanto, outro artigo não mostrou associações entre ansiedade e medidas autorreferidas de ade-são ${ }^{58}$.

$O$ processo de estigmatização refere-se à desvalorização de um indivíduo com
Assim, o tratamento do HIV não pode ser restrito aos aspectos médicos da doença, mas requer também uma grande atenção no funcionamento psicossocial, uma vez que esses fatores têm grande impacto na capacidade dos pacientes de tolerar e participar efetivamente da TARV.

base em características físicas e pessoais, consideradas inaceitáveis sociais, relacionadas a rea-ções negativas, julgamentos morais e discriminação ${ }^{63}$. O status sorológico para o HIV pode ser devastador para a vida familiar, social e econômica dos indivíduos, e esse es-tigma é citado como uma grande barreira para o acesso a serviços de prevenção, assis-tência e tratamento, manifestando-se como estigma socializado e internalizado ${ }^{64}$.

Com base nesse conceito, um estudo realizado no Peru constatou que o estigma global (social) não estava associado à não adesão, mas a subescala de estigma da divulgação negativamente associada à adesão perfeita ${ }^{21}$. Além disso, alguns dos estudos analisa-dos encontraram resultados divergentes, demonstrando não haver associação entre es-tigma e adesão ${ }^{7,18}$.

Outros estudos também encontraram que o medo de revelar o status sorológico por causa do estigma associado à doença é um importante contribuinte para a não adesão da TARV ${ }^{65,66}$. É sedutor especular que aqueles que não revelam seu status sorológico para os outros vivem continuamente com medo e perdem doses com base em preocu-pações sobre alguém descobrir seu estado de HIV ${ }^{21}$. Além disso, há mais pesquisas que reforçam a associação negativa entre estigma e adesão ${ }^{66-68}$.

\section{CONCLUSÃO}

Os fatores de saúde mental associados à não adesão à TARV são o uso de álcool e dro-gas, depressão, estigma e ansiedade, dos quais o uso de álcool e a depressão são os mais relevantes. Crenças de que o álcool e as drogas não podem ser misturados à TARV, atrasam o retorno de medicamentos e aquisição de prescrições da farmácia, ignorar a realidade, questionar a necessidade da TARV, falta de discernimento sobre a progressão do HIV, comprometimento da capacidade das pessoas à medicação da TARV conforme instruída são descobertas importantes nesse contexto que interferem na adesão.

Assim, o tratamento do HIV não pode ser restrito aos aspectos médicos da doença, mas requer também uma grande atenção no funcionamento psicossocial, uma vez que esses fatores têm grande impacto na capacidade dos pacientes de tolerar e participar efetivamente da TARV. Portanto, a avaliação e o tratamento de fatores psicossociais devem ocorrer durante o acompanhamento da terapia de novos pacientes e também ser parte integrante da rotina e da continuidade do tratamento do HIV. 


\section{REFERÊNCIAS}

1. Marrero-Severo, A., Delgado-Moya, E.M., modelo estocástico para la epidemia del VIH/SIDA.2017.chromeextension://ohfgljdgelakfkefopgklcohadegdpjf/https://www.scielo.sa.cr/pdf/rmta/ v24n2/1409-2433-rmta-24-02-00277.pdf.

2. Alves DN, Bresani-Salvi CC, Batista J d. AL, et al. Use of the Coding Causes of Death in HIV in the classification of deaths in Northeastern Brazil. Rev Saude Publica. 2017;51:88. doi:10.11606/S1518-8787.2017051000124

3. Costa RHS, Nelson ARC, Da Costa Prado NC, Rodrigues EHF, Da Silva RAR. Nurs-ing diagnoses and their components in acquired immune deficiency syndrome patients. ACTA Paul Enferm. 2016;29(2):146-153. doi:10.1590/19820194201600021

\section{UNAIDS. Ending AIDS. 2017.}

5. Brasil. Protocolo Clínico e Diretrizes Terapêuticas para Manejo da Infecção pelo HIV em Adultos | Departamento de Doenças de Condições Crônicas e Infecções Sexualmente Transmissiveis. http://www.aids.gov.br/pt-br/pub/2013/protocolo-clinico-e-diretrizes-terapeuticas-para-manejo-da-infeccao-pelo-hiv-em-adultos. Published 2017. Accessed Au-gust 13, 2020.

6. Sá Bandeira ACPC, Dias Elias DB, Cavalcante MG, Lima DGL, Távora LGF. An-tiretroviral changes during the first year of therapy. Rev Assoc Med Bras. 2017;63(7):606-612. doi:10.1590/1806-9282.63.07.606

7. Nunes AA, Caliani LS, Nunes MS, da Silva AS, de Mello LM Análise do perfil de pa-cientes com HIV/Aids hospitalizados após introdução da terapia antirretroviral (HAART). Ci-enc e Saude Coletiva. 2015;20(10):3191-3198. doi:10.1590/1413812320152010.03062015

8. Osorio J, Álvarez D, Barreto-Mora J, et al. Pulmonary infections in patients with HIV, 20 years after combined antiretroviral therapy. What has changed? Infectio. 2016;20(3):180-189. doi:10.1016/j.infect.2015.08.002

9. Segurado AC, Cassenote AJ, De Albuquerque Luna E. Saúde nas metrópoles-Doenças infecciosas. Estud Avancados. 2016;30(86):29-49. doi:10.1590/S0103-40142016.00100003

10. Medeiros RC da SC de, Medeiros JA de, Silva TAL da, et al. Quality of life, socioeco-nomic and clinical factors, and physical exercise in persons living with HIV/AIDS. Rev Saude Publica. 2017;51:66. doi:10.1590/S1518-8787.2017051006266

11. Santos WM dos, Secoli SR, Padoin SM de M. Potenciais interações de drogas em pacientes de terapia antirretroviral. 2016 chrome-extension://ohfgljdgelakfkefopgklcohadegdpjf/https:// www.scielo.br/pdf/rlae/v24/pt_0104-1169-rlae-24-02832. pdf.

12. Sagarduy JLY, López JAP, Ramírez MTG, Dávila LEF. Psychological model of ART adherence behaviors in persons living with HIV/AIDS in Mexico: a structural equation analysis. Rev Saude Publica. 2017;51:81. doi:10.11606/S15188787.2017051006926
13. Terto V. Diferentes prevenções geram diferentes escolhas? Reflexões para a preven-ção de HIV/AIDS em homens que fazem sexo com homens e outras populações vulnerá-veis. Rev Bras Epidemiol. 2015;18:156-168. doi:10.1590/18094503201500050012

14. Andrade DC de, Moraes. Terapia Antirretroviral: A Associação entre o Conhecimento e a Adesão. Journalof Res Fundam CareOnLine, Rio Gd do Norte, v 7, n 4, p 3563 - 3573. 2015. doi:10.9789/2175-5361.2015.v7i4. 3563-3573

15. Foresto JS, Melo ES, Costa CRB, Antonini M, Gir E, Reis RK. Adesão à terapêutica antirretroviral de pessoas vivendo com HIV/aids em um município do interior paulista. Rev Gauch Enferm. 2017;38(1):e63158. doi:10.1590/19831447.2017.01.63158

16. Calvetti PÜ, Giovelli GRM, Gauer GJC, de Moraes JFD. Níveis de ansiedade, estres-se percebido e suporte social em pessoas que vivem com HIV/AIDS. Psicol Teor e Pesqui. 2016;32(4):1-4. doi:10.1590/0102.3772e324317

17. Moher D, Liberati A, Tetzlaff J, Altman DG. Preferred Reporting Items for Systematic Reviews and Meta-Analyses: The PRISMA Statement. PLoS Med. 2009;6(7):e1000097. doi:10.1371/journal.pmed.1000097

18. Kleinman NJ, Manhart LE, Mohanraj R, et al. Antiretroviral therapy adherence meas-urement in non-clinical settings in South India. AIDS Care - Psychol Socio-Medical Asp AIDS/HIV. 2015;27(2):248-254. doi:10.1080/09540121.2014.946382

19. Teshome $W$, Belayneh $M$, Moges $M$, et al. Who takes the medicine? Adherence to antiretroviral therapy in Southern Ethiopia. Patient Prefer Adherence. 2015;9:1531-1537. doi:10.2147/PPA.S90816

20. Kalichman SC, Amaral CM, White D, et al. Alcohol and Adherence to Antiretroviral Medications: Interactive Toxicity Beliefs Among People Living With HIV. J Assoc Nurses AIDS Care. 2012;23(6):511-520. doi:10.1016/j.jana.2011.11.005.

21. Ferro EG, Weikum D, Vagenas $P$, et al. Alcohol use disorders negatively influence antiretroviral medication adherence among men who have sex with men in Peru. AIDS Care - Psychol Socio-Medical Asp AIDS/HIV. 2015;27(1):93-104. doi:10.1080/09 540121.2014 .963013$.

22. Kekwaletswe CT, Morojele NK. Alcohol use, antiretroviral therapy adherence, and preferences regarding an alcohol-focused adherence intervention in patients with human im-munodeficiency virus. Patient Prefer Adherence. 2014;8:401-413. doi:10.2147/PPA.S55547.

23. Tran BX, Nguyen LT, Do CD, Nguyen Q Le, Maher RM. Associations between alcohol use disorders and adherence to antiretroviral treatment and quality of life amongst people living with HIV/AIDS. BMC Public Health. 2014;14(1):27. doi:10.1186/1471-2458-14-27.

24. Pefura-Yone EW, Soh E, Kengne AP, Balkissou AD, Kuaban C. Non-adherence to antiretroviral therapy in Yaounde: Prevalence, determinants and the concordance of two screening cri- 


\section{REFERÊNCIAS}

teria. J Infect Public Health. 2013;6(4):307-315. doi:10.1016/j. jiph.2013.02.003.

25. Roux P, Lions C, Cohen J, et al. Impact of HCV treatment and depressive symptoms on adherence to HAART among HIV-HCV-coinfected patients: Results from the ANRSC013-HEPAVIH cohort. Antivir Ther. 2014;19(2):171-178. doi:10.3851/IMP2699.

26. Dagli-Hernandez C, Lucchetta RC, de Nadai TR, Galduróz JCF, Mastroianni P de C. Self-perception of knowledge and adherence reflecting the effectiveness of antiretroviral therapy. Patient Prefer Adherence. 2016;10:1787-1793. doi:10.2147/ PPA.S112108.

27. Magidson JF, Blashill AJ, Safren SA, Wagner GJ. Depressive Symptoms, Lifestyle Structure, and ART Adherence Among HIV-Infected Individuals: A Longitudinal Mediation Analysis. AIDS Behav. 2014;19(1):34-40. doi:10.1007/s10461-0140802-3.

28. Marks King R, Vidrine DJ, Danysh HE, et al. Factors associated with nonadherence to antiretroviral therapy in HIV-positive smokers. AIDS Patient Care STDS. 2012;26(8):479-485. doi:10.1089/apc.2012.0070.

29. Kim MH, Mazenga AC, Yu X, et al. High self-reported non-adherence to antiretroviral therapy amongst adolescents living with HIV in Malawi: Barriers and associated factors. J Int AIDS Soc. 2017;20(1). doi:10.7448/IAS.20.1.21437.

30. Pellowski JA, Kalichman SC, Kalichman MO, Cherry C. Alcohol-antiretroviral therapy interactive toxicity beliefs and daily medication adherence and alcohol use among people living with HIV. AIDS Care - Psychol Socio-Medical Asp AIDS/HIV. 2016;28(8):963-970. doi:10.1080/09540121.2016.1154134.

31. Paolillo EW, Gongvatana A, Umlauf A, Letendre SL, Moore DJ. At-Risk Alcohol Use is Associated with Antiretroviral Treatment Nonadherence Among Adults Living with HIV/AIDS. Alcohol Clin Exp Res. 2017;41(8):1518-1525. doi:10.1111/acer.13433.

32. Sharma A, Sachdeva RK, Kumar M, Nehra R, Nakra M, Jones $\mathrm{D}$. Effects of lifetime history of use of problematic alcohol on HIV medication adherence. J Int Assoc Provid AIDS Care. 2014;13(5):450-453. doi:10.1177/2325957413491430.

33. Kalichman SC, Grebler T, Amaral CM, et al. Intentional Non-Adherence to Medica-tions among HIV Positive Alcohol Drinkers: Prospective Study of Interactive Toxicity Beliefs. I Gen Intern Med. 2013;28(3):399-405. doi:10.1007/s11606-0122231-1.

34. Tufano CS, do Amaral RA, Cardoso LRD, Malbergier A. A influência dos sintomas depressivos e do uso de substâncias na adesão à terapia antirretroviral. Um estudo transver-sal de prevalência. Sao Paulo Med J. 2015;133(3):179-186. doi:10.1590/1516-3180.2013.7450010.

35. Kalichman SC, Kalichman MO, Cherry C, et al. Intentional medication nonadherence because of interactive toxicity beliefs among HIV-positive active drug users. J Acquir Im-mune Defic Syndr. 2015;70(5):503-509. doi:10.1097/

\section{QAl.0000000000000776.}

36. Moore DJ, Blackstone K, Woods SP, et al. Methamphetamine use and neuropsychiat-ric factors are associated with antiretroviral non-adherence. AIDS Care - Psychol Socio-Medical Asp AIDS/HIV. 2012;24(12):1504-1513. doi:10.1080/0954 0121.2012 .672718 .

37. Montoya JL, Georges S, Poquette A, Depp CA, Atkinson $J \mathrm{H}$, Moore DJ. Refining a personalized mHealth intervention to promote medication adherence among HIV+ metham-phetamine users. AIDS Care - Psychol Socio-Medical Asp AIDS/HIV. 2014;26(12):1477-1481. doi:10.1080/09540121.2014.92421 3.

38. Mimiaga MJ, Reisner SL, Grasso C, et al. Substance use among HIV-infected pa-tients engaged in primary care in the United States: Findings from the centers for AIDS Re-search Network of Integrated Clinical Systems Cohort. Am J Public Health. 2013;103(8):1457-1467. doi:10.2105/AJPH.2012.301162.

39. Newville H, Berg KM, Gonzalez JS. The Interaction of Active Substance Use, De-pression, and Antiretroviral Adherence in Methadone Maintenance. Int J Behav Med. 2015;22(2):214222. doi:10.1007/s12529-014-9429-z.

40. Hansana V, Sanchaisuriya P, Durham J, et al. Adherence to antiretroviral therapy (ART) among people living with HIV (PLHIV): A cross-sectional survey to measure in Lao PDR. BMC Public Health. 2013;13(1):617. doi:10.1186/1471-2458-13617.

41. Batista J d. AL, de Albuquerque M de FPM, Santos ML, et al. Associação entre taba-gismo e o uso de crack com a descontinuidade da terapia antirretroviral combinada em Reci-fe, Pernambuco, Brasil. Rev Inst Med Trop Sao Paulo. 2014;56(2):127132. doi:10.1590/S0036-46652014000200007.

42. Jordan MR, Obeng-Aduasare $Y$, Sheehan $H$, et al. Correlates of non-adherence to antiretroviral therapy in a cohort of HIV-positive drug users receiving antiretroviral therapy in Hanoi, Vietnam. Int J STD AIDS. 2014;25(9):662-668. doi: $10.1177 / 0956462413516301$.

43. Gebrezgabher BB, Kebede Y, Kindie M, Tetemke D, Abay M, Gelaw YA. Determi-nants to antiretroviral treatment non-adherence among adult HIV/AIDS patients in northern Ethiopia. AIDS Res Ther. 2017;14(1):16. doi:10.1186/s12981-0170143-1.

44. Dewing S, Mathews C, Lurie M, Kagee A, Padayachee T, Lombard C. Predictors of poor adherence among people on antiretroviral treatment in Cape Town, South Africa: A case-control study. AIDS Care - Psychol Socio-Medical Asp AIDS/HIV. 2015;27(3):342-349. doi:10.1080/09540121.2014.994471.

45. Mukui IN, Ng'ang'a L, Williamson J, et al. Rates and Predictors of Non-Adherence to Antiretroviral Therapy among HIV-Positive Individuals in Kenya: Results from the Second Kenya AIDS Indicator Survey, 2012. Thielman NM, ed. PLoS One. 2016;11(12):e0167465. doi:10.1371/journal.pone.0167465.

46. Magidson JF, Saal W, Nel A, Remmert JE, Kagee A. Relation- 


\section{REFERÊNCIAS}

ship between depres-sive symptoms, alcohol use, and antiretroviral therapy adherence among HIV-infected, clinic-attending patients in South Africa. J Health Psychol. 2017;22(11):14261433. doi:10.1177/1359105316628743.

47. Bonn-Miller MO, Oser ML, Bucossi MM, Trafton JA. Cannabis use and HIV antiretro-viral therapy adherence and HIV-related symptoms. J Behav Med. 2014;37(1):1-10. doi:10.1007/ s10865-012-9458-5.

48. Azar P, Wood E, Nguyen $P$, et al. Drug use patterns associated with risk of non-adherence to antiretroviral therapy among HIV-positive illicit drug users in a Canadian setting: A longitudinal analysis. BMC Infect Dis. 2015;15(1). doi:10.1186/s12879015-0913-0.

49. Teixeira C, Dourado MDL, Santos MP, Brites C. Impact of use of alcohol and illicit drugs by AIDS patients on adherence to antiretroviral therapy in Bahia, Brazil. AIDS Res Hum Retroviruses. 2013;29(5):799-804. doi:10.1089/aid.2012.0296.

50. Kader R, Govender R, Seedat S, Koch JR, Parry C. Understanding the Impact of Hazardous and Harmful Use of Alcohol and/or Other Drugs on ARV Adherence and Disease Progression. Andrei G, ed. PLoS One. 2015;10(5):e0125088. doi:10.1371/ journal.pone.0125088.

51. Moraes M., Oliveira AC., Tostes M. AIDS e psiquiatria. In: Prática Psiquiátrica no Hospital Geral: interconsulta e emergência. São Paulo Ed ARTMED, p373-394. 2006;2.ed.

52. Morrison MF, Petitto JM, Ten Have T, et al. Depressive and anxiety disorders in women with HIV infection. Am J Psychiatry. 2002;159(5):789-796. doi:10.1176/appi.ajp.159.5.789.

53. Betancur MN, Lins L, Oliveira IR de, Brites C. Quality of life, anxiety and depression in patients with HIV/AIDS who present poor adherence to antiretroviral therapy: a cross-sectional study in Salvador, Brazil. Brazilian J Infect Dis. 2017;21(5):507514. doi:10.1016/j.bjid.2017.04.004.

54. Whetten K, Shirey K, Pence BW, et al. Trauma History and Depression Predict In-complete Adherence to Antiretroviral Therapies in a Low Income Country. Dowdy DW, ed. PLoS One. 2013;8(10):e74771. doi:10.1371/journal.pone.0074771.

55. Belenky NM, Cole SR, Pence BW, Itemba D, Maro V, Whetten K. Depressive symp-toms, HIV medication adherence, and HIV clinical outcomes in Tanzania: A prospective, ob-servational study. PLoS One. 2014;9(5). doi:10.1371/journal. pone.0095469.

56. Tedaldi EM, Van Den Berg-Wolf M, Richardson J, et al. Sadness in the SUN: Using computerized screening to analyze correlates of depression and adherence in HIV-infected adults in the united states. AIDS Patient Care STDS. 2012;26(12):718729. doi:10.1089/apc.2012.0132

57. Wendorf AR, Mosack KE. Navigating hazardous conditions: Understanding hiv medi-cation adherence in the context of depression. Qual Health Res. 2013;23(4):541-554. doi:10.1177/1049732312469462
58. Kacanek $\mathrm{D}$, Angelidou $\mathrm{K}$, Williams $\mathrm{PL}$, et al. Psychiatric symptoms and antiretroviral nonadherence in US youth with perinatal HIV: A longitudinal study. AIDS. 2015;29(10):12271237. doi:10.1097/QAD.0000000000000697.

59. Fawzi MCS, Ng L, Kanyanganzi F, et al. Mental health and antiretroviral adherence among youth living with HIV in Rwanda. Pediatrics. 2016;138(4). doi:10.1542/peds.2015-323.

60. Willie TC, Overstreet NM, Sullivan TP, Sikkema KJ, Hansen NB. Barriers to HIV Med-ication Adherence: Examining Distinct Anxiety and Depression Symptoms among Women Living with HIV Who Experienced Childhood Sexual Abuse. Behav Med. 2016;42(2):120-127. doi:10.1080/08964289.2015.1045823..

61. Sauceda JA, Wiebe JS, Simoni JM. Childhood sexual abuse and depression in Latino men who have sex with men: Does resilience protect against nonadherence to antiretroviral therapy? J Health Psychol. 2016;21(6):1096-1106. doi:10.1177/1359105314546341

62. Panigrahi M, Swain T, Mohanty S. Nonadherence to anti-HIV medication is associated with higher level of anxiety: Experience from a tertiary care hospital of Odisha. Indian J Pharmacol. 2015:47(6):672-675. doi:10.4103/0253-7613.169578.

63. Corrigan PW, Watson AC. The Paradox of Self-Stigma and Mental IIIness. Clin Psy-chol Sci Pract. 2006;9(1):35-53. doi:10.1093/clipsy.9.1.35.

64. Mahajan AP, Sayles JN, Patel VA, et al. Stigma in the HIV/ AIDS epidemic: a review of the literature and recommendations for the way forward. AIDS. 2008;22 Suppl 2(Suppl 2):S67. doi:10.1097/01.aids.0000327438.13291.62.

65. McKinney O, Modeste NN, Lee JW, Gleason PC, Maynard-Tucker G. Determinants of antiretroviral therapy adherence among women in southern malawi: Healthcare providers' perspectives. AIDS Res Treat. 2014;2014. doi:10.1155/2014/489370.

66. Denison JA, Koole O, Tsui $S$, et al. Incomplete adherence among treatment-experienced adults on antiretroviral therapy in Tanzania, Uganda and Zambia. AIDS. 2015;29(3):361-371. doi:10.1097/QAD.0000000000000543.

67. Bofill LM, Lopez M, Dorigo A, et al. Patient-provider perceptions on engagement in HIV care in Argentina. AIDS Care - Psychol Socio-Medical Asp AIDS/HIV. 2014;26(5):602-607. doi:10. 1080/09540121.2013.844767.

68. Bogart LM, Wagner GJ, Green HD, Mutchler MG, Klein DJ, McDavitt B. Social Net-work Characteristics Moderate the Association Between Stigmatizing Attributions About HIV and Non-adherence Among Black Americans Living with HIV: a Longitudinal Assessment. Ann Behav Med. 2015;49(6):865-872. doi:10.1007/s12160-015-9724-1

69. Gross WTA, Ng C, Saha SR, Colford JM. Treatment outcomes after highly active an-tiretroviral therapy: A meta-analysis of randomised controlled trials. Lancet Infect Dis. 2004;4(7):414425. doi:10.1016/S1473-3099(04)01057-6. 